\title{
Using a participatory approach to develop a sustainability framework for carbon capture and storage systems in The Netherlands
}

\author{
Andrea Ramírez ${ }^{a, *}$, Monique Hoogwijk $^{b}$, Chris Hendriks ${ }^{b}$, André Faaij $^{a}$ \\ ${ }^{a}$ Copernicus Institute, Utrecht University, Heidelberglaan 2, 3584 CS Utrecht, The Netherlands \\ ${ }^{b}$ Ecofys B.V., P.O. Box 8408, 3503 RK Utrecht, The Netherlands
}

\section{A R T I C L E I N F O}

\section{Article history:}

Received 12 March 2007

Received in revised form

16 July 2007

Accepted 10 August 2007

Published on line 27 September 2007

Keywords:

Sustainability criteria

Interactive policy making

Carbon capture and storage

\begin{abstract}
A B S T R A C T
Sustainability considerations guide political decisions concerning energy supply options. In this article a start has been made for the development of a sustainability framework for carbon capture and storage (CCS) systems in the Netherlands. Using a participatory approach (which includes an exploratory workshop, two interactive meetings, an international survey and in-depth interviews), nine sustainability criteria for CCS based energy systems were defined and 36 main concerns about the sustainability of carbon, capture and storage systems (by criterion) were identified. Analysis shows that concerns related to the following criteria are most relevant: clean, flexible, just, competitive and publicly acceptable. Furthermore, via stakeholder consultations and through interviews, a list of actions to tackle the concerns was developed. These actions can be clustered into three groups: (i) increasing research and development, (ii) including CCS in a policy portfolio, and (iii) raising public awareness. Finally, actions that should take place in the next 2 years were identified.
\end{abstract}

(C) 2007 Elsevier Ltd. All rights reserved.

\section{Introduction}

Sustainable development has become the main policy paradigm since the nineties. Ever since the publication in 1987 of the Brundtland report (WCED, 1987), sustainable development has been taken up by many authorities and interest groups and translated into policy targets. In the discussion of how to reach sustainability, the central role that energy plays is increasingly recognized ${ }^{1}$ because (i) lack of access to diverse and affordable energy services means that the basic needs of billions of people are not being met; (ii) energy services are a key motor of economic growth, needed to create jobs, develop industries, enhance value added activities and support income-earning activities; and (iii) the environmental effects of energy use can occur at many levels, from the household to global, and include consequences such as desertification, acidification, air pollution and climate change (WEHAB, 2002). Furthermore, the potential of climate change has been characterized as one of the main threats for sustainable development due to its severity, time dimensions and irreversibility.

Our current energy system is highly dependent on fossil fuels and unsustainable. It is therefore not surprising that changing these conditions has become a target in energy policy. For instance, the last European Union Green Paper on

\footnotetext{
* Corresponding author. Tel.: +31 30 2537639; fax: +31 302537601.

E-mail address: c.a.ramirez@uu.nl (A. Ramírez).

${ }^{1}$ The role of energy in reaching sustainability has been affirmed at a number of UN conferences/agreements. For instance: the UN Framework Convention on Climate Change (1992); the Global Conference on Sustainable Development of Small Island Developing States (1994); World Summit on Social Development (1995); the UN Conference on Human Settlements (1996); Kyoto protocol (1997); the Millennium Declaration (2000); the Third United Nations Conference on the Least Developed Countries (2001); the Commission in Sustainable Development, 9th session (2001); and the World Summit on Sustainable Development (2002).

1750-5836/\$ - see front matter (C) 2007 Elsevier Ltd. All rights reserved.
}

doi:10.1016/S1750-5836(07)00097-7 
energy identifies three main objectives for the European energy policy: (i) sustainability, (ii) competitiveness, and (iii) security of supply (EC, 2006). Energy efficiency improvements and further implementation of renewables are valuable options in the development of a more sustainable and secure energy system, but their introduction may take long. Since the early 1990s, carbon capture and storage (CCS) has entered the policy debate. CCS involves the recovery of $\mathrm{CO}_{2}$ from (fossil energy) conversion processes and its disposal away from the atmosphere, e.g. in depleted oil or gas fields, aquifers or deepocean. This concept enables the prolonged use of fossil fuels but with reduced carbon dioxide emissions, thus providing the time needed for the large-scale deployment of renewables and the implementation of efficiency improvements (e.g. Hennicke and Fischedick, 2006; Turkenburg, 1997).

The following arguments in favour of CCS can be found in the literature (e.g. Bachu, 2000; Metz et al., 2005; Turkenburg, 1997):

- CCS could be deployed at a considerable scale in the coming decades;

- The $\mathrm{CO}_{2}$ storage capacity is large;

- CCS could be a cost-effective answer to high carbon-tax;

- CCS allows for continuing large scale use of fossil fuels giving the time to switch to other forms of energy supply;

- CCS can be a low cost mitigation option if hydrogen were to become a major energy carrier; it could be necessary on longer terms if other options fail (e.g. if energy sources such as wind or nuclear energy cannot gain sufficient market share and/or acceptance);

- CCS does not depend on local climate conditions, does not compete with agriculture, fishing, other industries and land use;

- Provided that the storage location is chosen carefully, CCS is auditable.

Nonetheless, CCS also has a number of less attractive features for example that it is essentially an end-of-pipe waste management response for $\mathrm{CO}_{2}$ emissions, it does not reduce $\mathrm{CO}_{2}$ production itself and the reliance on fossil fuels remains (a security of supply issue). Hence it is not clear how CCS systems will fit into a transition to a sustainable energy supply. Despite this, CCS in some form is increasingly considered to be necessary if the $\mathrm{CO}_{2}$ abatement targets in the medium to longer term are to be met. At the moment there are only a handful of publications dealing with the sustainability of energy systems still based on fossil fuel sources (e.g. German Council for Sustainable Development, 2003; Jaccard, 2005; PowerClean et al., 2004). In the Netherlands, the government envisions achieving a sustainable energy system in the long term via an energy transition which may include CCS (EZ, 2005). In this paper, we do not argue that CCS is per se a sustainable option but that its implementation could play an important role in the transitions towards the development of a sustainable energy supply. In this context, the research question that guides this paper is: if CCS is to play a substantial role in the development of a sustainable energy system in the Netherlands, which criteria should be fulfilled? To be able to answer this question, we developed a sustainability framework for the implementation of CCS. This framework is made up of a set of clear sustainability criteria that can be subsequently operationalized by indicators. Such a framework has not yet been developed. The following sub-questions have been posed to address the issue effectively:

1. Which criteria determine the sustainability of an energy system?

2. What concerns should be addressed if CCS is to be part of a sustainable energy system or a transition towards a sustainable energy system?

3. Which actors should undertake what actions to overcome these concerns?

\section{Methodology}

The development of such a framework has been divided into two phases (Table 1). The first phase aims to define sustainability criteria, identify main concerns that would make a CCS system unsustainable, and identify early actions that need to be made in order to overcome the concerns. This

Table 1 - A sustainability framework as defined in this article

\begin{tabular}{|c|c|c|c|c|c|c|c|}
\hline \multicolumn{5}{|c|}{ FIRST PHASE } & \multicolumn{3}{|c|}{ SECOND PHASE } \\
\hline Criteria & Definition & Ranking & $\begin{array}{c}\text { Main } \\
\text { concerns }\end{array}$ & $\begin{array}{c}\text { Early } \\
\text { actions }\end{array}$ & Indicators & Weights & Trade-offs \\
\hline $\bar{a}$ & $\begin{array}{l}\text { This criteria means } \\
\text { that }\end{array}$ & 1 & $\begin{array}{l}\text { - } \\
\text { - }\end{array}$ & $\begin{array}{ll}\cdot & 1 \\
\cdot & 2\end{array}$ & $\begin{array}{cc}\cdot & \mathrm{A} \\
\cdot & \beta \\
\cdot & \mathrm{C}\end{array}$ & $\begin{array}{ll}\cdot & \text { A1 } \\
\cdot & \text { B2 } \\
\cdot & \text { C3 }\end{array}$ & \\
\hline $\mathrm{b}$ & $\begin{array}{l}\text { This criteria means } \\
\text { that }\end{array}$ & 2 & $\begin{array}{l}\text { - } \\
\text { - } \\
\end{array}$ & $\begin{array}{ll}\cdot & 3 \\
\cdot & 4 \\
\cdot & 5 \\
\end{array}$ & - $\gamma$ & $\begin{array}{l}\cdot \quad \gamma 1 \\
\cdot \quad \gamma 2\end{array}$ & \\
\hline$\cdots$ & & & - & - & - & - & \\
\hline $\bar{n}$ & $\begin{array}{l}\begin{array}{l}\text { This criteria means } \\
\text { that }\end{array} \\
\end{array}$ & 10 & $\begin{array}{l}\text { - } \mathrm{X} \\
\text { - }\end{array}$ & $\begin{array}{cc}\cdot & 9 \\
\text { - } & 10\end{array}$ & $\begin{array}{l}\text { - } \mathrm{K} \\
\cdot \vec{\lambda}\end{array}$ & $\begin{array}{ll}\cdot & \mathrm{K} 1 \\
\cdot & \Lambda 1\end{array}$ & 4 \\
\hline
\end{tabular}




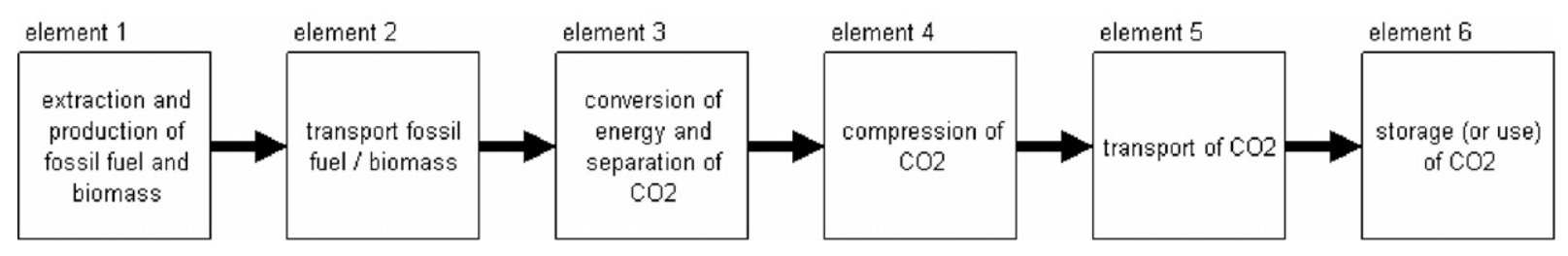

Fig. 1 - The chain of CCS as used in this study, indicating the different elements.

phase also includes a preliminary prioritization of the criteria as well as an inventory of the opinions and visions of different stakeholders with respect to CCS. In a second phase, the criteria will be made operational by developing indicators, assigning weights and identifying trade-offs. Also in the second phase an analysis of several case studies will be made in order to identify robust methodologies that can be used to monitor the sustainability of CCS systems. This paper reports the results of Phase 1 which was conducted between March 2005 and September 2006. Results of the second phase are expected by end of 2008 .

The starting point for this research is the recognition that formulating a sustainability framework cannot only be the result of a scientific exercise made by a single institution. The importance of early stakeholder involvement in the formulation of targets for sustainability assessments of complex systems has been pointed out in several studies (e.g. Lewandowski and Faaij, 2004; United Nations, 2001). There are two main reasons: (i) a sustainability definition must be developed context specific and according to the priorities and perceptions of the relevant actors towards sustainability (the importance assigned to various criteria may differ depending on specific regional conditions and needs), and (ii) many sustainability criteria, especially concerning social issues, require normative decisions which cannot be made by scientific judgment alone (e.g. descriptions of criteria which contain aspects such as fairness, equity and justice). Furthermore, for systems such as CCS where uncertainty is prevalent, information is incomplete and knowledge is diverse, the involvement of different actors allow for a better treatment of information because it is unlikely that one actor possesses the perfect overview. Taking all these aspects into account, we selected a participatory approach for the development of a national sustainability framework for CCS.

A participatory approach should fulfill a series of characteristics (Geurts and Mayer, 1996):

- The analysis should be decision-oriented and stimulate broad framing of the policy problem. A broad overview of available scientific insights should be developed;

- Options should be developed which are different, relevant and internally consistent;

- The method should allow step-by-step learning and should allow for the participation of the relevant stakeholders;

- It should facilitate communication in which the judgments of experts and stakeholders are taken into account; and finally

- The method should allow for the integration of scientific data and judgment of experts and stakeholders.
The Dutch stakeholders ${ }^{2}$ involved during the development of the sustainability framework were: the government (Ministry of Economic Affairs, Ministry of Environment, SenterNovem); industry (steel industry (Corus), oil and gas industry (Shell international, NoGePa)); the power sector (Electrabel Nederland, Nuon and Delta); research institutions (Clingendael International Energy Programme, the Energy Center of the Netherlands, the Netherlands Environmental Assessment Agency, the Netherlands Organization for Applied Scientific Research, the Rathenau Institute, Groningen University, Technical University of Delft, University of Twente, University of Leiden and Utrecht University); and environmental NGOs (Netherlands Society for Nature and Environment and Greenpeace).

Before describing the different activities in detail, it is important to define the system boundaries of the mitigation option as it is used in this article. The IPCC Special Report on CCS gives the following definition: "CCS is a process consisting of the separation of $\mathrm{CO}_{2}$ from industrial and energy-related sources, transport to a storage location and long-term isolation from the atmosphere" (Metz et al., 2005). In setting up the framework for sustainability, we expanded the definition of CCS because the influence of capture and storing $\mathrm{CO}_{2}$ is not limited to the actual separation, transport and storage activities. The other important elements we included were the (continuing) extraction, transport and use of fossil fuel. The boundaries of CCS used in this analysis are depicted in Fig. 1. The following CCS chain elements are distinguished: Elements 1-3 represent the fossil fuel or biomass production, transportation and conversion to secondary energy carriers, e.g. electricity, heat or hydrogen. During or after the conversion, the $\mathrm{CO}_{2}$ is captured from the process and compressed (element 4), transported (element 5), and stored or used (element 6). It should also be noted that ideally the transport and use of secondary energy carriers should be taken into account because hydrogen, in particular, may have further implications for the system. However, this aspect has been neglected in this research.

In this research, we opted for a multi-method approach consisting of the following activities: (i) a literature review, (ii) an exploratory workshop, (iii) two interactive meetings, (iv) a survey, and (v) in-depth interviews. Fig. 2 depicts how the different activities are linked to each other and to the results. An overview of the stakeholders involved by type of activity is shown in Table 2.

\footnotetext{
${ }^{2}$ Stakeholders are defined as agents which have a professional interest in CCS through employment or personal engagement in a voluntary capacity (Coninck et al., 2006).
} 


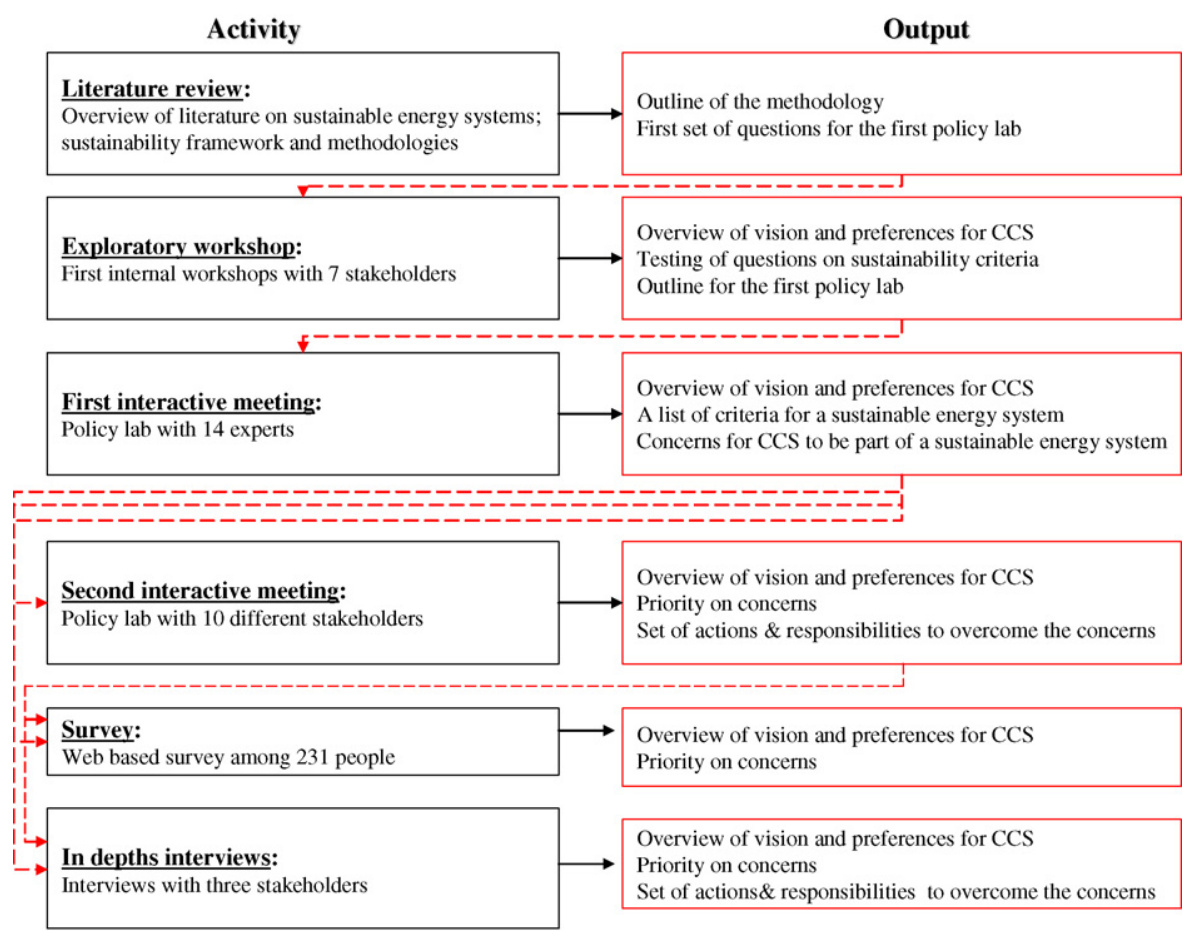

Fig. 2 - Links between the different activities and their results.

\subsection{Exploratory workshop}

A small exploratory workshop was held in July 2005. It aimed to point out the main issues of concern regarding the role of CCS in a sustainable energy system and targeted a select number of stakeholders (three people from the power industry, two from the government, two from academia and one from an environmental NGO). The results of the workshop, in combination with the literature scan, were used to shape the interactive meetings.

\subsection{Interactive meetings}

Two interactive meetings were conducted in November 2005 and March 2006 using a Group Support System (GSS-also known as policy lab or collaborative computing). GSS brings a decision-making group together in a room outfitted with a set of hardware (a network system and a computer for each participant involved), software (tools which enable electronic brainstorming and structuring of ideas-for the two interactive meetings we used the software GroupSystems $\AA$ ) and process facilitation (preparation and management of the electronic meeting). GSS addresses typical problems of face-to-face meetings such as domination by one or a few members (which tends to inhibit participation), poor interpersonal communication, poor planning and organization of the meeting, and reluctant to express innovative ideas. GSS enables teams to reduce their efforts in applying quality improvement methods by providing automated means to enter, record and build on team members ideas during face-to-face meetings. It enables stakeholders to comment on others' ideas in parallel and anonymously (the anonymity should encourage participants to speak freely) and it records automatically all information that process through the system for future analysis. In addition to the electronic exchange of information, 'normal' conversation also takes place. GSS has been used since the mid-1980s. Applications include arriving at potential solutions to financial problems at a university (Lewis, 1982), evaluating the future

Table 2 - Overview of the stakeholder consultations within this project

\begin{tabular}{|c|c|c|c|c|c|c|}
\hline \multirow[t]{2}{*}{ Activity } & \multirow[t]{2}{*}{ Number of participants } & \multicolumn{5}{|c|}{ Stakeholder type } \\
\hline & & Industry & Power sector & Government & Research & NGO \\
\hline Exploratory workshop & 7 & & $\mathrm{x}$ & $\mathrm{x}$ & $\mathrm{x}$ & $\mathrm{x}$ \\
\hline Interactive meetings & & & & & & \\
\hline First policy lab & 14 & & & & $\mathrm{x}$ & \\
\hline Second policy lab & 10 & $\mathrm{x}$ & $\mathrm{x}$ & $\mathrm{x}$ & $\mathrm{x}$ & \\
\hline Survey & 231 & & $\mathrm{x}$ & $\mathrm{x}$ & $\mathrm{x}$ & $\mathrm{x}$ \\
\hline Interviews & 3 & & & $\mathrm{x}$ & & $\mathrm{x}$ \\
\hline
\end{tabular}



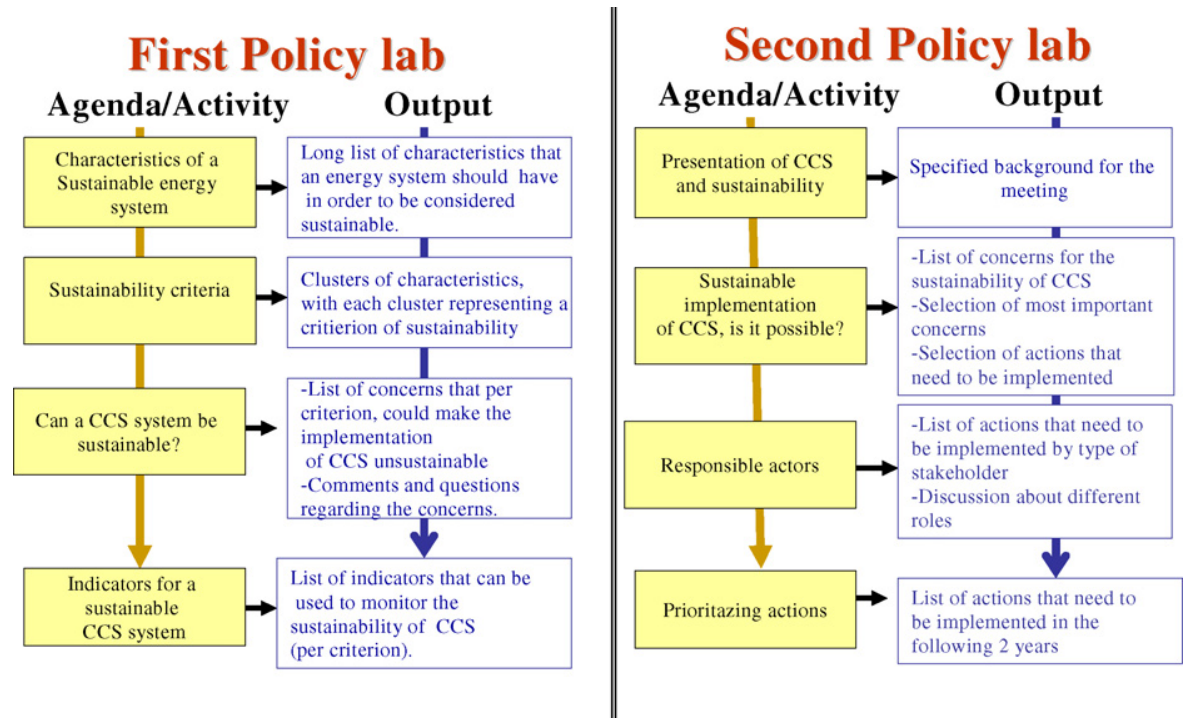

Fig. 3 - Agenda points and main output expected of the interactive meetings.

European automobile industry (Vickers, 1992), assessing uncertainty in communicating information (Wardekker and van der Sluijs, 2006), and developing alternative future scenarios for international biomass trade (Heinimö et al., 2007). Further information on GSS can be found in Bigdoli (1996), Colleman and Khanna (1995), Dennis and Wixom (2001), DeSantics and Gallupe (1987) and Huber (1984).

In the first interactive meeting 14 specialists in different fields of expertise participated (e.g. pollution, risk assessment, transition management, energy infrastructure, energy economists, and public acceptance). The goal of the meeting was two-fold. First, to define the criteria that an energy system must fulfill in order to be considered sustainable. Second, to identify the main concerns (by criterion) that would make the implementation of CCS unsustainable.

The second interactive meeting was designed for stakeholders (i.e. 10 policy-makers from organizations such as power utilities, chemical companies, research institutions, local associations, etc.). Departing from the sustainability criteria and concerns generated in the first interactive meeting (see Fig. 2), the second GSS aimed to (i) obtain the visions of different stakeholders on the main concerns for the sustainable implementation of CCS, and (ii) to identify the responsibilities (which actors are responsible for what) and actions that need to be implemented if CCS is to be deployed in a sustainable way. An overview of the main agenda points of each session and the expected results are shown in Fig. 3.

\subsection{An international survey}

An international survey was conducted between December 2005 and March 2006 to obtain a preliminary hierarchy among the concerns about the sustainability of CCS expressed by the stakeholders in the workshop and the interactive meetings. The survey was also used to gather data on the visions and preferences of the respondents with respect to the role of CCS in reducing $\mathrm{CO}_{2}$ emissions. The survey was conducted in both paper form and through the Internet. ${ }^{3}$

\subsubsection{Survey design and coverage}

The target group of the survey was people working in climate policy, energy analysis, energy policy, climate change, carbon capture and storage, and development of technologies for carbon dioxide abatement. It is important to highlight that this group already has (some) knowledge of climate change related issues (i.e. what is climate change, what options are available for the abatement of greenhouse emissions, what is carbon capture and storage) and therefore it is not a representative sample of the 'common' citizen in the Netherlands or abroad. ${ }^{4}$ The main characteristics of the survey sample are shown in Box 1.

The survey consisted of three parts. The first part (six questions) aimed to gather data on the background of the respondents. The second part (five questions) addressed the vision on the role of CCS in the energy system during the next century. In the final part (nine questions), respondents were asked to select their main concerns regarding CCS and the sustainability of the energy system. The survey questionnaire can be found in Appendix A. The time designed to complete

\footnotetext{
${ }^{3}$ The survey was distributed during the first Dutch National Clean Fossil Fuel Day (1 November 2005) and by Internet to students of the Master Program on Sustainable Development (Utrecht University); participants to the 8th International Conference on Greenhouse Gas Control Technologies; and to experts linked to the IPCC report on climate change. The response rate was of about $45 \%$.

${ }^{4}$ To investigate the view of the 'common' citizen on the sustainability of CCS a different kind of approach has to be designed (e.g. information choice questionnaires). Research has shown that 'current public opinions on CCS, assessed by traditional questionnaires, are mostly pseudo-opinions: they are unstable, and are affected by tiny amounts of non-diagnostic information and by the mood of the respondent' (Best-Waldhober et al., 2006, p. 14). For detailed information we refer to Best-Waldhober et al. (2006), Reiner et al. (2006) and Schackley et al. (2005).
} 


\section{Box 1. Characteristics of the survey sample}

- Number of respondents: 231 (116 from the Netherlands and 115 distributed among 29 different nationalities).

- Employed by: scientific/research sector (48\% TS, 35\% $\mathrm{DR})$, the power sector (10\% TS, 14\%DR); the oil and chemical industry ( $9 \% \mathrm{TS}, 10 \% \mathrm{DR})$, the government (7\% TS, 9\% DR), consultancy/an engineering company (12\% TS, $13 \% \mathrm{DR})$, environmental organization (4\% TS, $3 \% \mathrm{DR})$, other $(10 \% \mathrm{TS}, 17 \% \mathrm{DR})$.

- Work orientation: technical (52\% TS, $46 \%$ DR), economical (6\% TS, 6\% DR), social (5\% TS, 9\% DR), policy ( $17 \%$ TS, $18 \% \mathrm{DR})$, environmental ( $12 \% \mathrm{TS}, 9 \% \mathrm{DR})$, others ( $8 \%$ TS, $12 \% \mathrm{DR})$.

- Field of expertise: technology (53\% TS, $41 \%$ DR), legal issues ( $2 \% \mathrm{TS}, 3 \% \mathrm{DR})$, economic feasibility and finances ( $9 \% \mathrm{TS}, 10 \% \mathrm{DR})$, risk aspects $(5 \% \mathrm{TS}, 3 \%$ $\mathrm{DR})$, policy (15\% TS, 16\% DR), management (3\% TS, $5 \% \mathrm{DR})$, others (13\% TS, $22 \% \mathrm{DR})$.

- Working time spend on CCS issues: less than $25 \%$ time (52\% TS, 67\% DR); $25-50 \%$ time (11\% TS, 9\% DR); 50-75\% time $(11 \% \mathrm{TS}, 10 \% \mathrm{DR})$, and more than $75 \%$ time $(26 \%$ TS, $13 \% \mathrm{DR})$.

Note. TS: total sample; DR: Dutch respondents

the survey was around $10 \mathrm{~min}$ and included 20 multiplechoice questions.

We use the third part of the survey to obtain a preliminary hierarchy among the criteria. Note that we did not ask the respondents to select between criteria such as clean or safe because each respondent can have a different understanding of what each criterion exactly means and hence we will be unable to obtain comparable results. Instead, we opted for translating the criteria into concerns (those expressed by stakeholders during the exploratory workshop and the interactive meetings) and asking the respondents to select among four concerns at a time, which is in their opinion the most relevant. In all cases the respondents were obliged to select one of the concerns over the others since the option 'none of them' was not available. A list of the questions and concerns used is shown in Table 4.

The results cannot only be analyzed per question, but also by the number of times that each criterion was chosen. This is accomplished by developing frequency distributions for each respondent and for the total sample. For instance, respondent $\mathrm{X}$ chooses concerns linked to the criterion clean three times, safe two times, public acceptance one time, competitiveness three times (the other criteria were not selected). Note that adding all frequencies will give a 9. In other words, among nine points, respondent $\mathrm{X}$ has given three points to the criterion clean, three to competitiveness, one to publicly acceptable, two to safety and zero to the rest. The distribution of nine points among the different criteria will be used to interpret the survey's results in Section 4.

\subsubsection{Statistical analysis}

Sigmastat for Windows (version 3.11) was used to analyze the results of the survey. In order to decide which statistical tests would be applied to the sample, we tested whether the population followed a standard bell shaped Gaussian distribution. Sigmastat uses the Kolmogorov-Smirnov test (with Lilliefors' correction) to test data for normality. ${ }^{5}$ The results pointed out that the population did not show a normal distribution and therefore, when comparing the differences among variables we selected tests that do not assume the samples to be drawn from normal populations: the MannWhitney Rank Sum Test and the Kruskal-Wallis Analysis of Variance on Ranks. ${ }^{6}$

\subsection{In-depth interviews}

Finally, three in-depth interviews with stakeholders from the Ministry of Economic Affairs, the Ministry of Housing, Planning and the Environment, and the Netherlands Society for Nature and Environment were conducted to further understand specific issues of concern that emerged during the workshop and the interactive meetings. The interviews focused on the identification of the most important concerns, actions and responsible actors for the sustainable implementation of CCS. Of special importance was to obtain a list of actions (together with the responsible actors) that should be implemented in the next 2 years.

\section{Visions and preferences for the role of CCS in the energy system}

What is the vision of the stakeholders involved in this project on the role of CCS? Perception affects the way in which sustainability is defined and which trade-offs are considered acceptable. Therefore a part of the research has focused on extracting the visions and preferences with respect to CCS among different groups. From the survey's results we found that:

- The majority of respondents (58\% total sample; $63 \%$ Dutch respondents) considered CCS an important option because it creates greater lead-time to develop cost-effective renewables. Twenty-nine percent of the total respondents $(22 \%$ from the Dutch sample) perceive the importance of CCS lies in that it can be deployed on a large scale, while the minority considers the opportunities to exploit technical know-how

\footnotetext{
${ }^{5}$ This test compares the cumulative distribution of the data with the expected cumulative Gaussian distribution, and bases its $P$ value on the largest discrepancy.

${ }^{6}$ The Mann-Whitney Rank Sum Test is used to test for a difference between two groups that is greater than what can be attributed to random sampling variation. The null hypothesis is that the two samples were not drawn from populations with different medians. This test ranks all the observations from smallest to largest without regard to which group each observation comes from. The ranks for each group are summed and the rank sums compared. If there is no difference between the two groups, the mean ranks should be approximately the same. If they differ by a large amount, one can assume that the low ranks tend to be in one group and the high ranks in the other, and conclude that the samples were drawn from different populations. The Kruskal-Wallis Analysis of Variance on Ranks is essentially the same as a Mann-Whitney Rank Sum Test, except that there are more than two experimental groups. The null hypothesis tested is that there is no difference in the distribution of values between the different groups.
} 
at the national level a key factor ( $12 \%$ of the total sample, $16 \%$ of the Dutch respondents).

- The role of CCS in reducing $\mathrm{CO}_{2}$ emissions is considered comparable to the role of energy saving and renewables by the majority of respondents (80\% total sample; $76 \%$ of the Dutch sample), while $14 \%$ of the total responders and Dutch respondents consider it THE solution to combat climate change, and $6 \%$ of the total sample ( $10 \%$ of the Dutch respondents) see it as a futile solution.

- Seventy percent of the total respondents and 67\% of the Dutch respondents expect that in the coming century CCS will play an important role as long as fossil fuels and storage capacity are available, while $26 \%$ of the respondents $(29 \%$ of the Dutch sample) expect it to play a temporary role and only $4 \%$ of the total sample (35\% of the Dutch respondents) expect that it will not play an important role at all.

- When asked for how long they hope that CCS will play a role, only $50 \%$ of the total respondents (36\% of the Dutch respondents) answered that they hoped CCS will play an important role as long as fossil fuels and storage capacity are available, $43 \%$ of the total sample $(58 \%$ of the Dutch respondents) hoped that it will play a temporary role and $7 \%$ of the total sample ( $6 \%$ of the Dutch respondents) hoped that it will not play a major role.

The last two bullets showed that there is a significant difference between what the respondents expect and hope the role of CCS to be in the coming century. This corroborates the notion that although energy generation by means of fossil fuels with CCS is considered a necessary option to achieve $\mathrm{CO}_{2}$ abatement targets, it is far away from being considered an ideal one. The position of the main stakeholders in the Netherlands can be summarized as follows ${ }^{7}$ :

- Government. Although it recognizes the importance of advanced technologies, including CCS, in addressing climate change, there is not a unified vision about the role that CCS could play. Different views also emerged for example between the Ministry of Housing, Planning and the Environment and the Ministry of Economic Affairs (which in the Netherlands is the entity responsible for designing and implementing energy policy).

- Environmental NGOs. Their role is to critically examine the option and the conditions under which CCS would be implemented in order to guarantee that the energy system will develop into a sustainable one. On average, NGOs perceive CCS as an option that may be necessary in a transition phase in order to obtain a significant share of the $\mathrm{CO}_{2}$ emissions reduction necessary for the medium term (e.g. 2020-2030), but stress than in the long term (2050-2100) the energy system should be kept within desired limits by means of increased energy efficiency and renewables. ${ }^{8}$ An important point is that CCS should not hinder in any way the (further) development and implementation of renewables

\footnotetext{
7 The inventory of positions of the different stakeholders in the Netherlands was made during the exploratory workshop, second policy lab and the in-depth interviews.

8 Typical examples of the NGOs position can be found on: Climate Action Network Europe (2006), Friends of the Earth et al. (2005) and Froggatt and Teske (2005).
}

and energy efficiency, for example by possible lower investments in renewables due to capital flowing to CCS.

- Scientists/research centers. The scientific and research communities recognize the potential role that CCS can play in addressing greenhouse gas emissions. They highlight the need for further research on economics, development of monitoring systems and technologies for $\mathrm{CO}_{2}$ capture.

- Oil and power companies. These companies play a major role in the implementation of CCS. They are cautious to take any definitive decision about CCS as long as there is no clarity on the $\mathrm{CO}_{2}$ policy (at the national and European level) and the value of $\mathrm{CO}_{2}$ reduction in the post Kyoto period. There is also a strong need to obtain and evaluate results from current demonstration projects.

\section{Criteria for sustainability and concerns for the CCS system}

Because of the threat of climate change and the social and economic importance of energy, the sustainability of energy systems has been a recurring subject of research. A literature scan of 53 papers and books published in the area shows several trends ${ }^{9}$ :

- About one third of the papers revised do not explicitly define sustainable development or a sustainable energy system. Among those that do, the most quoted definition comes from the Brundtland report: "Sustainable Development is development that meets the needs of the present without compromising the ability of future generations to meet their own needs" (WCED, 1987).

- Despite the many interpretations of sustainability, there is a broad consensus that sustainable development captures two important ideas:

- Sustainable development is a concept that involves at least three dimensions ${ }^{10}$ : economic, social and environmental.

- There is an obligation of the current generation toward future generations so that their well-being will be at least as high as our own.

- Despite a long list of characteristics, most authors emphasize a combination of the following aspects when characterizing a sustainable energy system:

- Security of supply: an energy system should be able to supply the basic energy needs of the population (for current and future generations).

- Minimization of environmental damage: the impacts of an energy system should not exceed the capacity of the ecosystems to absorb the effect without permanent damage.

- Resource availability: an energy system should use resources in such a way that the prospects of future generations to have (at least) access to energy services at the same level as current generations, are not threatend.

${ }^{9}$ Results of the review are worked out in detail in Ramírez et al. (2007).

10 In the literature there are also references to other dimensions, such as cultural, institutional and technological. 
Table 3 - Criteria and concerns for the sustainability of CCS systems

\begin{tabular}{|c|c|c|}
\hline Criteria & Definition & $\begin{array}{l}\text { Examples of concerns named by } \\
\text { stakeholders about CCS }\end{array}$ \\
\hline Clean & $\begin{array}{l}\text { Minimum burden for the environment in the } \\
\text { broad sense; reduction of emissions to the air, } \\
\text { soil and water. This includes amongst others } \\
\text { emissions that may contribute to the enhanced } \\
\text { climate change effect and air pollution. Clean } \\
\text { also includes the reduction of transport of } \\
\text { (dangerous) waste. This criterion has a time } \\
\text { and geographical dimension (no pollution for } \\
\text { future generations and other countries) }\end{array}$ & $\begin{array}{l}\text { CCS may lead to long environmental effects associated to } \\
\text { fossil fuel use that are not solved by the use of this technology } \\
\text { (e.g. mining, other pollutants such as aerosols, } \mathrm{NO}_{\mathrm{x}}, \mathrm{SO}_{\mathrm{x}} \text {, etc.) } \\
\text { At different parts of the } \mathrm{CCS} \text { chain, but especially during } \\
\text { storage, small losses of } \mathrm{CO}_{2} \text { can occur that still can } \\
\text { lead to significant emissions over longer time periods } \\
\text { There is a large demand for land area (which will be } \\
\text { adversely affected) during the mining of coal }\end{array}$ \\
\hline Safety & $\begin{array}{l}\text { Minimization of the negative health impacts } \\
\text { for humans and the prevention of catastrophe } \\
\text { occurrences. Special attention should be given } \\
\text { to the product of change and impact }\end{array}$ & $\begin{array}{l}\text { The possible consequences of unexpected releases of gas } \\
\text { are uncontrollable. Even if there is little change, the } \\
\text { consequences for humans and animals might be large } \\
\text { When CCS is used at large scale, the probability of leakage, } \\
\text { especially during transport and storage, might increase } \\
\text { The use of coal on a large scale is unsafe when considering } \\
\text { the accidents/deaths during mining }\end{array}$ \\
\hline Just & $\begin{array}{l}\text { Implies that there is both equity and } \\
\text { manageability between regions and generations. } \\
\text { The availability and accessibility of energy } \\
\text { should be the same for all regions and current } \\
\text { and future generations. Next to this, the risks } \\
\text { and possible negative impacts of the energy } \\
\text { system should also be equal. The energy supply } \\
\text { of the future should not lead to (increased) poverty }\end{array}$ & $\begin{array}{l}\text { Building a sustainable energy supply is postponed for future } \\
\text { generations when CCS is introduced on large scales } \\
\text { CCS is less accessible for less developed countries because } \\
\text { of the higher costs involved } \\
\text { There could be increased negative environmental impacts due } \\
\text { to extraction of fuels (especially coal) in other regions } \\
\text { (outside the Netherlands) }\end{array}$ \\
\hline Flexible & $\begin{array}{l}\text { Implies that the energy system has a diversity } \\
\text { of energy sources and carriers to decrease the } \\
\text { dependency on other regions for the current and } \\
\text { future energy supply system } \\
\text { The choices regarding the energy systems } \\
\text { that are made at this moment should not } \\
\text { cause any lock-in for future technologies } \\
\text { or institutional aspects }\end{array}$ & $\begin{array}{l}\text { Investments in CCS could lead to reduce investments in } \\
\text { other (more sustainable) options. It could optimize the current } \\
\text { situation further resulting in a suboptimal energy supply } \\
\text { system in the longer term }\end{array}$ \\
\hline Continuity & $\begin{array}{l}\text { Implies that energy sources are available } \\
\text { for longer timeframes and that there is } \\
\text { sufficient time for and insight in the } \\
\text { development of alternative sources }\end{array}$ & $\begin{array}{l}\text { CCS will lower the efficiency of the conversion process which } \\
\text { would deplete fossil fuels earlier } \\
\text { In the Netherlands, the potential for } \mathrm{CO}_{2} \text { storage could be limited } \\
\mathrm{CCS} \text { will probably be implemented on a large scale making } \\
\text { more difficult to implement decentralized supply systems }\end{array}$ \\
\hline Independence & $\begin{array}{l}\text { Implies that an energy system is not (too) } \\
\text { dependent on other regions for its } \\
\text { energy supply }\end{array}$ & $\begin{array}{l}\text { Because fossil fuels will still be the main energy carrier, } \\
\text { CCS will not contribute to a less fossil fuel dependent } \\
\text { energy system. It may even increase }\end{array}$ \\
\hline $\begin{array}{l}\text { Competitive position } \\
\text { or affordability }\end{array}$ & $\begin{array}{l}\text { Implies that energy is available at low costs } \\
\text { for consumers and that there is a level playing } \\
\text { field for industry and power companies }\end{array}$ & $\begin{array}{l}\text { CCS has high investment costs. It increases the electricity } \\
\text { production costs } \\
\text { CCS should especially play an important role in countries with } \\
\text { significant amount of coal as China and India. In these } \\
\text { countries affordability is especially a potential bottleneck } \\
\text { Although CCS is more expensive than energy saving measures, } \\
\text { it may decrease pressure to improve energy efficiency and } \\
\text { as a result lead to additional costs } \\
\text { If the investments in CCS technologies are not done at an } \\
\text { international scale, this might be adverse for the economy. } \\
\text { CCS is only possible if there is an international incentive } \\
\text { or policy for climate neutral energy supply }\end{array}$ \\
\hline Publicly acceptable & $\begin{array}{l}\text { The system should be acceptable for large } \\
\text { parts of the society, should be transparent } \\
\text { and guarantee the common interest }\end{array}$ & $\begin{array}{l}\text { CCS can have large local impacts (compression, transport } \\
\text { and storage). This is potential undesirable for local } \\
\text { environment and habitants } \\
\text { Parallels to nuclear waste disposal can be made by the public, } \\
\text { which could increase opposition by local communities }\end{array}$ \\
\hline Reliability & $\begin{array}{l}\text { Implies that the energy system supplies a } \\
\text { continue flow of energy. The complexity of the } \\
\text { system should not reduce the constant supply } \\
\text { of energy }\end{array}$ & $\begin{array}{l}\text { CCS Increases the complexity of power production which } \\
\text { could lead to increasing black-outs or increase the need } \\
\text { for more back-up power generation capacity }\end{array}$ \\
\hline
\end{tabular}


- Price affordability: there should be equal opportunities to access energy services for all society members and those services should be provided in such a way that support economic growth and employment.

- In comparing the multifaceted visions of sustainable development, the way the concept is framed in most papers places greater emphasis on the environmental pillar (compared with the economic or social pillar).

- Attempts to operationalize sustainable development assessments of energy systems usually involve a conceptual division into particular sustainabilities, excluding the integration of the ecological, economic and social dimensions. There is a lack of a conceptual framework that can reconcile the goals formulated in all of them.

- Despite frequent criticisms of sustainability implementation strategies developed without active participation of the stakeholders involved including local communities, most definitions, strategies, characteristics and/or indicators developed in the literature nonetheless did not include public participation as an active element during the formulation process.

In this context, the development of a sustainability framework for CCS systems in the Netherlands should at least: (i) make explicit the definition of sustainability used, (ii) include public participation as an active element, and (iii) give balanced attention to the three pillars of sustainable development (economic, social and environment).

In this research, to derive a consistent definition of a sustainable energy system, we focused on the criteria that a sustainable energy system must fulfill. Furthermore, the definition of the criteria used to characterize a sustainable energy system is the result of the participatory process with experts using a bottom up procedure during the first interactive meeting (first, brainstorming desired characteristics of a sustainable energy system, then grouping them into clusters and thirdly providing a name for each cluster). In this way, what is considered in each group (hereafter criterion) is explicitly formulated and thus avoids confusing terminology. The result is a list of nine criteria that together defines a sustainable energy system: "a sustainable energy system is a system that is clean, safe, reliable, just, affordable, and accepted by the public, and guarantees flexibility, continuity and independence".

The following step was to understand what concerns (per criterion) could make an energy supply system with CCS unsustainable. When this is known, it becomes possible to evaluate whether or not actions can be taken to overcome or prevent such problems. Table 3 shows the list of the sustainability criteria, the definitions of each criterion (as resulted from the first interactive meeting), and representative examples of the main concerns related to the implementation of large scale CCS (as resulted from the two interactive meetings). The concerns were provided by experts (first interactive meeting) and stakeholders (second interactive meeting and in-depth interviews). Note that the list of concerns does not imply that every concern is justified, valid and/or based on scientific evidence. It simply means that a (group of) stakeholder(s) in the Netherlands think those points need to be addressed because they could make a CCS system unsustainable.

\section{Preliminary hierarchy of sustainability criteria}

Implementing a CCS system that fulfils at once all sustainability criteria will be a daunting task to achieve. To implement a system that step-wise fulfills the criteria is a more realistic view. For this reason, we have used the results to gain preliminary insights into which concerns and related criteria are considered a priority. Table 4 shows the results of the selection of concerns by the respondents of the total sample (third column). Note that concerns associated with the criteria continuity, reliability, and safety were not selected as main worries (independent of the country of origin of the respondent) when compared with those associated with other sustainability criteria.

Table 4 is, in fact, a contingency table which also summarizes the concerns according to the type of organization the respondents were working for. Strong conclusions from the table are not easily derived, and although it is evident that the way participants selected concerns is influenced by the kind of organization they represent, to what level this influenced the selection made is not clear. In order to have a better understanding of the results, we have 'translated' the answers to the individual questions into frequencies as described in Section 2. This grouping provides a preliminary clustering of the sustainability criteria (see Figs. 4 and 5). It is important to highlight that the results of this 'translation' can only be used as a first guide of the relative importance of each criterion. To use these results for other purposes (e.g. by applying directly the distribution of weights to a multi criteria analysis) would go beyond a reasonable interpretation of the data. ${ }^{11}$

Fig. 3 depicts how the respondents of our survey prioritized the various criteria of Table 3 . The bars represent confidence intervals of $95 \%$. At a first sight, three clusters can be distinguished, with clean, flexible, just, competitiveness and publicly acceptable being prioritized the highest, followed by independence and continuity, and in last place, safe and reliable. These results at the cluster level are in agreement with the results provided in Table 4. Fig. 4 also shows whether the Dutch respondents would prioritize the criteria differently. We found that, statistically, the differences between the means of the groups 'Dutch respondents' and 'Other nationalities' are only significant for the criteria publicly acceptable and independence (P values are shown in Appendix B). In other words, the differences in the means for publicly acceptable and independence obtained for 'Dutch respondents' and 'Other nationalities' is greater than would be expected by chance (as is the case with the other seven criteria). Nonetheless, despite the statistic difference, the variability of the means is not big enough to change the rank order.

\footnotetext{
11 The manner in which the survey was designed implies that each concern statement is presented along with three other concern statements and respondents should select their biggest worry (i.e. forced to choose one out of four). Note that each concern (indicating a specific criterion) on its own provides no information about the importance of the chosen criterion; it merely indicates that the chosen worry is "bigger" than the three others (e.g. all four worries can be totally unimportant in the eyes of a respondent). Hence, although the data allows for a preliminary comparison of the frequency with which certain worried are selected, it is not suited to derive specific weights that could be used in multi criteria analysis.
} 
Concern selected by respondents according to the type of

(\% total

sample,

\begin{tabular}{|c|c|c|c|}
\hline $\begin{array}{l}\text { Power } \\
\text { sector }\end{array}$ & $\begin{array}{l}\text { Oil/chemical } \\
\text { industry }\end{array}$ & $\begin{array}{l}\text { Engineering } \\
\text { consultancy }\end{array}$ & $\begin{array}{l}\text { Government } \\
\quad(n=16)\end{array}$ \\
\hline
\end{tabular}

$(n=23)$

$(n=21)$

$(n=28)$

nstitution $(n=111)$

1 That there is no public acceptance for CCS

That there is no or little spin-off for renewable energy

That it impedes the implementation of solar and wind energy

That international pipelines are difficult to manage

2 That we stay dependent on fossil fuels

That $\mathrm{CO}_{2}$ leaks from underground reservoirs counteracting the effect of storage

That it impedes poor countries to develop their energy supply

That there is a danger for a large blow-out at the storage site

3 That the costs will have negative effects on our standards of living

That the storage capacity for $\mathrm{CO}_{2}$ is insufficient

That $\mathrm{CO}_{2}$ leaks to an adjacent drinking water reservoir

That $\mathrm{CO}_{2}$ pipelines cross populated areas that may prove to be dangerous

$4 \quad$ That it diverts attention away from energy saving

That poor countries do not have access to expensive CCS technology

That the price of electricity will increase too much

That it stimulates centralized large-scale energy supply (which might be less reliable than decentralized one)

5 That other environmental problems of energy supply are not solved

That the development of renewable energy systems will be impeded

That small-scale renewable energy will have little opportunity

That there are not sufficient fossil fuel resources available

6 That we will become dependent on regions with large amounts of storage capacity

That companies will not invest in this technology

That the balance of competition is disturbed

That casualties will continue to occur as a consequence of coal mining

7 That it doesn't solve the environmental issue due to the continuing pollution from extracting and transporting fossil fuels

That we remain dependent on regions with large fossil fuel resources

That environmental organizations are opposed to it

That power plants will become more complex resulting in more power failures

8 That we place a burden on future generations because of the $\mathrm{CO}_{2}$ stored underground

That fossil fuels will become expensive

That the supply of fossil fuels is unreliable

That storage locations will become a target for terrorist attacks

9 That other countries/regions will not implement CCS

That future generations have to bear the costs of a transition to an energy supply

based on renewables

That climate change is a hype and CCS not required after that

That industrial production processes shut down more often because of the increased complexity

\begin{tabular}{|c|c|c|c|c|c|c|}
\hline 45 & 63 & 71 & 35 & 29 & 47 & 11 \\
\hline 28 & 29 & 10 & 15 & 35 & 30 & 33 \\
\hline 17 & 8 & 5 & 27 & 29 & 13 & 56 \\
\hline 10 & 0 & 3 & 6 & 1 & 11 & 0 \\
\hline 49 & 41 & 52 & 46 & 46 & 50 & 22 \\
\hline 27 & 25 & 19 & 23 & 24 & 30 & 56 \\
\hline 16 & 21 & 19 & 23 & 18 & 15 & 0 \\
\hline 8 & 13 & 10 & 8 & 12 & 5 & 22 \\
\hline 33 & 58 & 47 & 38 & 24 & 28 & 33 \\
\hline 32 & 13 & 29 & 31 & 46 & 35 & 34 \\
\hline 22 & 25 & 19 & 12 & 18 & 20 & 33 \\
\hline 13 & 4 & 5 & 19 & 12 & 17 & 0 \\
\hline 48 & 33 & 33 & 54 & 59 & 52 & 67 \\
\hline 21 & 13 & 19 & 15 & 29 & 24 & 0 \\
\hline 21 & 50 & 29 & 23 & 12 & 13 & 22 \\
\hline 10 & 0 & 19 & 8 & 0 & 11 & 11 \\
\hline 44 & 33 & 47 & 54 & 41 & 43 & 56 \\
\hline 36 & 42 & 29 & 38 & 24 & 38 & 33 \\
\hline 13 & 8 & 24 & 4 & 29 & 12 & 0 \\
\hline 7 & 17 & 0 & 4 & 6 & 7 & 11 \\
\hline 42 & 13 & 13 & 0 & 41 & 22 & 22 \\
\hline 26 & 25 & 67 & 0 & 53 & 46 & 34 \\
\hline 22 & 58 & 10 & 100 & 0 & 20 & 22 \\
\hline 10 & 4 & 10 & 0 & 6 & 12 & 22 \\
\hline 34 & 29 & 14 & 38 & 35 & 37 & 56 \\
\hline 33 & 38 & 38 & 27 & 47 & 32 & 11 \\
\hline 25 & 29 & 43 & 23 & 18 & 24 & 11 \\
\hline 8 & 4 & 5 & 12 & 0 & 7 & 22 \\
\hline 58 & 58 & 38 & 58 & 53 & 57 & 56 \\
\hline 26 & 30 & 38 & 27 & 6 & 29 & 44 \\
\hline 13 & 8 & 14 & 15 & 29 & 13 & 0 \\
\hline 3 & 4 & 10 & 0 & 12 & 1 & 0 \\
\hline 52 & 75 & 66 & 30 & 0 & 54 & 0 \\
\hline 38 & 13 & 24 & 50 & 42 & 39 & 67 \\
\hline 6 & 8 & 5 & 8 & 58 & 5 & 33 \\
\hline 4 & 4 & 5 & 12 & 0 & 2 & 0 \\
\hline
\end{tabular}




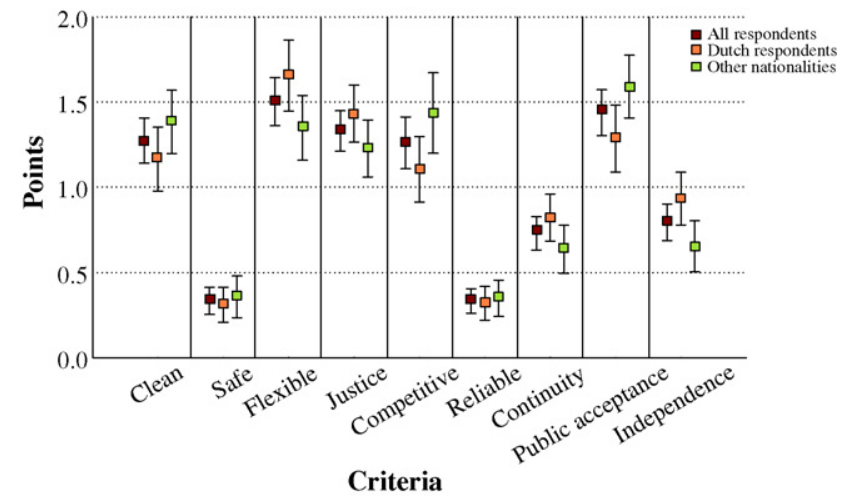

Fig. 4 - Distribution of frequency points among sustainability criteria for the total sample and for the groups 'Dutch respondents' and 'other nationalities'.

We also analyzed whether the results are dependent on the kind of stakeholder (e.g. NGO vs. Government). Fig. 5 plots the prioritization of the criteria related to the type of organization. The figure provides a clearer picture of the influence of this factor on the results than Table 4. As expected, for those sectors that can implement CCS (the power sector and the oil and chemical industry), clean, competitiveness and flexible are ranked the highest. Interestingly, the power and oil and chemical industry ranked publicly acceptable higher than all other sectors. The criteria independence, flexible and just were ranked the highest by the governmental sector while clean, just, competitiveness and flexible were the criteria ranked in first place by environmental organizations. Note that the confidence intervals are much bigger for the individual groups than for the total respondents, which is a reflection of the size of the sample. For instance, only $4 \%$ of the sample works for environmental organizations (4\%), while $48 \%$ work for the scientific/research sector.

Since publicly acceptable and independence are the criteria showing significant statistical differences between the Dutch and non-Dutch respondents, we have taken a closer look to

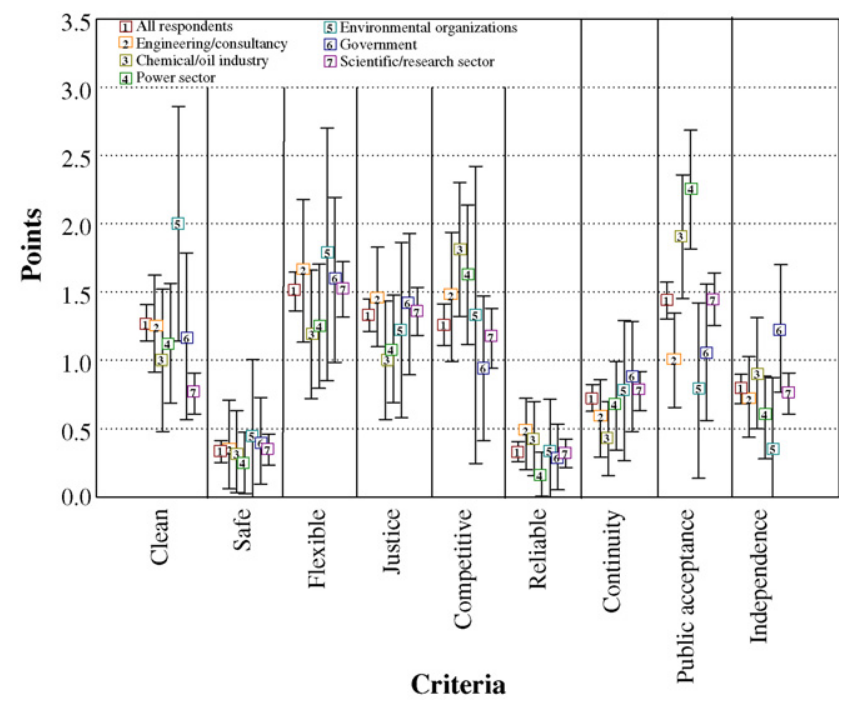

Fig. 5 - Distribution of frequency points among sustainability criteria according to organization. these two criteria, now according to the type of organization (e.g. chemical/oil industry, power sector, government, research) and nationality (i.e. Dutch vs. non-Dutch respondents). We found that in only one case there were significant statistical differences among Dutch and non-Dutch stakeholders. NonDutch respondents working for the chemical and oil industry gave a significantly larger weight to the criterion Public Acceptance than Dutch ones (Pvalues are shown in Appendix C).

We have also evaluated whether the prioritization of the different criteria is affected by the perceptions the respondents have on the role of CCS for the next century. In other words, do the respondents expectations (or hopes) for the future role of CCS affect how they distribute the weights among the different criteria ${ }^{12}$ Our findings are summarized below (results of the statistical tests are shown in Appendix D): - The frequency with which concerns related to the criteria clean, safe, independence and reliable were selected is independent of whether the respondents hope/expect the role of CCS to be important, temporal or not important.

- The weight allocation to the criteria continuity and publicly acceptable are dependent on the respondents' hopes/expectations for the role of CCS. Respondents who hope/expect CCS will play a temporal role more frequently selected the criterion continuity than respondents who hope/expect an important role. In contrast, the criterion publicly acceptable was selected less frequently by those who hope/expect a temporal role and more frequently by those who hope/ expect an important role. Additionally, we found a significant difference in the respondents' selected concerns related to the criterion publicly acceptable between the groups 'important role' and 'non-important role', with the former group selecting this parameter more frequently (this is only the case when participants were asked about their hope for the role of CCS, when asked for their expectations, no significant differences are found between the groups).

- For the criteria just and competitiveness, there are only differences in the way the criteria are prioritized when respondents were asked about their hopes on the role of CCS for the next century (when asked for their expectations, no differences are found among the groups). The difference is found between the groups 'hoping that CCS will play an important role' and 'hoping that CCS will play a temporal role'. For the criterion just, respondents who hope CCS will play a temporal role selected the concerns related to this criterion more frequently than those respondents hoping for an important role. For the criterion competitiveness, the highest weight is allocated by those respondents hoping for an important role of CCS.

Summarizing, the frequency with which concerns regarding the criteria clean, safety, independence and reliable is not affected by the respondents' perception of the future role of CCS. Respondents who hope/expect CCS to play a temporary role in the energy system tend to more frequently select concerns related to the criteria continuity and just than those

\footnotetext{
12 There are three kind of roles assigned to CCS in the survey: (i) an important role as long as fossil fuels and storage capacity is available, (ii) a temporary role and (iii) that it will not play an important role in the next century.
} 
who hope/expect an important role for CCS. On the other hand, respondents who hope/expect CCS to play an important role as long as fossil fuels and storage capacity are available tend to select more frequently concerns related to the criteria publicly acceptable and competitiveness than those expecting/ hoping for a temporal role.

Finally, the low frequency with which concerns regarding safety issues were selected is striking (when compared to other sustainability criteria). Safety is a recurrent point of discussion in almost all literature and debates concerning CCS. This low ranking seems to be independent of the nationality, the type of organization of the respondents or the role they hope or expect for CCS in the next century. The low ranking could be due to the belief that with the current technology and increased knowledge about characteristics of the sequestration sites, safety requirements could be more easily fulfilled than other sustainability concerns and hence safety does not appear as a big threat to the sustainability of the system. The low ranking does not imply that no further research or measures are required to increase safety of CCS systems.

\section{Roles and responsibilities}

In addition to defining sustainability criteria and identifying concerns for the sustainability of CCS systems, we have also examined how stakeholders see their role and responsibilities for the implementation of different actions. To do so, stakeholders were asked during the second interactive meeting and in the in-depth interviews to identify (i) actions to overcome the main concerns for the implementation of CCS as part of (a transition towards) a sustainable energy system, and (ii) the actors responsible for carrying out these actions. This exercise resulted in the definition of three groups of actions:

1. Increasing research and development (R\&D);

2. Including CCS in a policy portfolio (national and international) and in current or new legal frameworks;

3. Raising public awareness and improving public acceptance.

\subsection{Increasing research, development and demonstration}

Not surprisingly the first group of actions pointed out by most stakeholders are related to R\&D. In order to reduce the energy efficiency penalty and high investment costs, more research and development is required. This encompasses both demonstration projects and more academic research. Although the main technological components for CCS deployment (i.e. capture technology, pipelines, injection) have already been available and deployed worldwide, they have not been yet demonstrated together in an integrated energy generation system. Increasing commercial experience with assessing the complete chain is thus considered important. In addition, because experience with $\mathrm{CO}_{2}$ storage is limited, monitoring and on-site testing during demonstration projects are needed to improve the knowledge of the storage capacities and the safety of storage sites (see for instance Damen et al., 2006). Summarizing, this type of action would focus on three criteria: clean (efficiency improvement); safety (testing storage sites and developing monitoring systems) and competitiveness (reducing the high investment costs, improving efficiency of the entire CCS chain).

\subsection{Including CCS in a policy portfolio (national and international) and in current or new legal frameworks}

This second group includes actions related to the creation of policy and legal frameworks. As pointed out by stakeholders from the industry and power companies during the workshop and the second interactive meeting, CCS will only be implemented on a large( $\mathrm{r}$ ) scale when $\mathrm{CO}_{2}$ has a price. The inclusion of CCS in the EU Emissions Trading Schemes (ETS) is therefore indispensable. The current ETS system does not give credits for CCS and several issues must be resolved before this happens (e.g. volatility of the $\mathrm{CO}_{2}$ market must be addressed because it can hinder long term investments). Similar remarks were done for the inclusion of CCS in the Clean Development Mechanism (CDM).

At a national scale, it was mentioned that a subsidy such as a feed in tariff needs to be implemented. These subsidies should be guaranteed at the longer term to create security for market players. However, it should be noted that subsidies of this kind will most likely be opposed by environmental NGOs. In fact, one of the main points that has been made by NGOs such as Greenpeace and the Netherlands Society for Nature and Environment is that subsidies should not be given for the implementation of CCS (with the exception of subsidies for $\mathrm{R} \& \mathrm{D}$ and demonstration projects). This statement is based on the "polluter pays principle" (i.e. energy and main industrial sectors should bear the financial weight of CCS deployment). Hence, subsidies should only be set aside for 'sustainable' energy initiatives (i.e. primarily low-impact renewable energy, energy efficiency and conservation) for which public investment is needed to mobilize large-scale deployment across the economy. Furthermore, the Netherlands Society for Nature and Environment stated that CCS should be presented as one option within a portfolio of greenhouse gas mitigation options, next to renewable energy sources. The portfolio (and not CCS as such) should be the main framework of the greenhouse gas mitigation policy. An additional point made was that in current legislation on waste or treatment of offshore areas, storage of $\mathrm{CO}_{2}$ is not included (changes in the legislation have begun although at a rather slow pace). ${ }^{13}$ Furthermore, to guarantee safety and storage over a longer period of time, monitoring is very important. This needs to be institutionalized including the development of necessary standards. ${ }^{14}$ The responsibilities and liabilities related to sudden impacts and

\footnotetext{
${ }^{13}$ Actions of this type have already begun. For instance, a resolution on an Amendment to Annex 1 of the 1996 Protocol to the London Convention to include $\mathrm{CO}_{2}$ sequestration in sub-seabed geological formations (which recognized that CCS is an important mitigation option and expressed the desire for regulation of CCS) was adopted on the 2 November 2006.

14 At this respect the European Commission in its Decision C (2004)130 [M\&R Guidelines] invites "Member States interested in the development [of M\&R guidelines for CCS] to submit research findings to the Commission". The Department of Trade and Industry of the UK has undertaken a study that reviews monitoring requirements and proposed a set of guidelines for EC to consider for adoption by member states. No outcome is available yet.
} 
Table $\mathbf{5}$ - The most urgent actions for deployment of CCS for the coming $\mathbf{2}$ years including the responsible stakeholder as mentioned in the in-depth interviews

\begin{tabular}{lll} 
Actions & \multicolumn{1}{c}{ Responsible actor } & Related criteria \\
\hline $\begin{array}{l}\text { Inclusion of CCS in EUs ETS system } \\
\text { Improve insights into the affordability of CCS } \\
\quad \text { and under what } \mathrm{CO}_{2} \text { regime }\end{array}$ & $\begin{array}{l}\text { Government (international) } \\
\text { Research institutions }\end{array}$ & $\begin{array}{l}\text { Competitiveness } \\
\text { Competitiveness }\end{array}$ \\
$\begin{array}{l}\text { Develop standards related to safety and monitoring } \\
\text { and institutionalise responsibilities related to }\end{array}$ & Government (international) & Safe \\
$\quad$ unwanted $\mathrm{CO}_{2}$ releases & & \\
$\begin{array}{l}\text { Implement demonstration projects } \\
\text { Include CCS in legal national and international } \\
\text { frameworks (e.g. ETS, CDM) }\end{array}$ & Industry & Covernment (international: EU) \\
$\begin{array}{l}\text { Increase public awareness } \\
\text { Research on efficiency improvements }\end{array}$ & All stakeholders competitiveness \\
\hline
\end{tabular}

disasters should also be clear before starting large scale implementation.

Summarizing this group of actions focuses on the criteria competitiveness (providing some kind of financial guarantees to lower the threshold for investment in CCS and reducing vulnerability to the political decision-making); safety (developing and implementing a reporting, monitoring and verification system for CCS systems, in particular for the storage of $\mathrm{CO}_{2}$ ) and just (increasing technological development by means of CDM projects). National and international governmental bodies are considered responsible for implementing CCS in the ETS and CDM, for subsidies and legal approval, as well as for monitoring systems.

\subsection{Raising public awareness and improving public acceptance}

This third group of actions is considered crucial for the largescale implementation of CCS by all actors. National and local resistance can arise related to risks brought by this option (e.g. leakage) and by impacts of infrastructural works. An open and transparent decision-making process related to impacts in the short, medium and long-term should be guaranteed in order to avoid/minimize local resistance to concrete project(s). When informing the public, open communication is important (already important when starting demonstration projects). When communicating CCS to a broader public, a key message should be that all greenhouse gas mitigation options and measures are required when combating climate change. It was also mentioned that a stepwise introduction of CCS might be an approach to gradually become more acquainted with the technology.

A relevant question is who should play what role in raising public awareness and support. Ter Mors (2004), for instance, has examined whether the credibility of CCS organizations maters for attitude formation (similar lines of research are being carried out in the UK and Australia). Among the main conclusions are: (i) people will lack the ability (e.g. due to lack of knowledge, experience, time constraints) to form attitudes systematically towards CCS and will use heuristics (e.g. "messengers from experts can be trusted", "messages that people agree to are right", "the longer the message the more valid it is"); (ii) it is likely that people will use the credibility of the source of communication as a heuristic; (iii) The credibility of CCS organizations will (directly or indirectly) influence attitudes. Hence, although no individual actor was mentioned during the workshops and in-depth interviews to be solely responsible for this, stakeholders from the government and scientific community have highlighted the importance of NGO support when informing the general public. A supportive position of NGOs could minimize conflicts since it has been found that among stakeholders industry and government tend to be trust the least by the common citizen while environmental NGOs and scientific organizations are perceived as the most trusted (e.g. Ter Mors et al., 2005; Trumbo and McComas, 2003). Environmental NGOs therefore have a crucial role in the public debate and need to be actively involved in the decision-making process from the start.

So far, the list of actions obtained during the interactive meetings has a rather general character. In order to specify further, we used the in-depth interviews to obtain a list of concrete actions for the coming 2 years. The results are shown in Table 5. For stimulating implementation and for improving the competitiveness of CCS, primarily policy makers and research institutions should take early actions. Policy makers need to guarantee a sufficiently high price for $\mathrm{CO}_{2}$ and are considered responsible for the standards and guidelines for risk management and monitoring. There is call for research institutions to improve the efficiency of CCS and analyze the costs and cost reduction potential for CCS. There is a role for industry to increase their knowledge of the implementation of the entire chain by starting demonstration projects. The improvement of public acceptance is seen as an action that involves all stakeholders.

\section{Conclusions}

Carbon capture and storage is a mitigation option that has gained interest over the last decade. Whether CCS can contribute towards sustainable development of energy systems is an important but complex policy question. In this study, a start has been made to develop a sustainability framework for the implementation of CCS in the energy system. By using the framework a (more objective) consideration can be made regarding if and how CCS can contribute to a sustainable energy system. The framework is been developed in close discussion with experts on 
sustainability and CCS, and with the relevant actors involved in the development and deployment of CCS. In this study the following steps were performed: (i) compilation of a set of criteria, which form the basic elements of the framework; (ii) identification of the concerns for implementation of CCS with respect to its contribution to a sustainable energy system, which has been done per criteria; (iii) preliminary prioritization of the criteria, based on survey and workshop discussions; (iv) identification of required actions to address the concerns. Also, for each action the actors were identified who are considered to have the principal responsibility to initiate the action.

Based on a literature review, discussion and workshops with relevant stakeholders, a definition of a sustainable energy system based on a set of nine criteria was developed: "a sustainable energy system is a system that is clean, safe, reliable, just, affordable, and accepted by the public, and guarantees flexibility, continuity and independence". For each criterion, experts and stakeholders identified a list of 36 concerns. Each posses a (perceived) possible barrier for the implementation of CCS in a sustainable way. The concerns that were selected as the most troublesome by the respondents of the survey are:

- Whether or not there will be sufficient public acceptance for CCS;

- The energy system will remain dependent on fossil fuels;

- The increased costs will have negative effects on our standards of living;

- CCS diverts attention away from energy saving and renewable energy;

- Other environmental problems of current fossil energy supply are not addressed by CCS such as local air pollution and mining operations;

- The energy system may become dependent on regions with large amounts of storage capacity;

- We may place a burden on future generations because of the $\mathrm{CO}_{2}$ stored underground;

- Other countries/regions will not implement CCS.

Analysis shows that concerns related to the criteria clean, flexible, just, competitiveness and publicly acceptable were considered most relevant. The selection of concerns is influenced by the type of organization the respondents work for. This is an important point since it implies that for balanced and unbiased evaluation of sustainability of energy supply systems with CCS, heterogeneity in the stakeholder group that participates in the decision-making process should be guaranteed.

Notably, among the most troublesome concerns selected by the respondents, those related to safety were not found. The apparent (relatively) low priority of safety cannot and should not be understood as a call for no action with respect to this criterion. In fact, in both the policy sessions and the in-depth interviews there was a constant call for increasing knowledge on the testing and monitoring of underground storage (to minimize/avoid consequences of possible $\mathrm{CO}_{2}$ leakage). The low frequency with which concerns related to safety were selected in the survey could be due to the perception (of most actors) that with the current technology and increased knowledge about characteristics of the storage sites and safety, the requirements can more easily be fulfilled than other sustainability concerns. Furthermore, the choice in the survey of one worry among four merely indicates that the chosen worry is considered more troublesome than the other three and thus does not imply that the concerns not selected should be disregarded.

In stakeholder consultations and interviews we discussed the actions required to overcome the concerns. These actions can be clustered in three groups: (i) increasing research and development, (ii) including CCS in a policy portfolio, and (iii) raising public awareness. The government is generally seen as the most relevant stakeholder for the first phase of implementation of CCS (in a sustainable way). Apart from some small niche markets, CCS will add to the costs of energy production and will therefore need a strong policy support. Early actions should include (per stakeholder group):

\section{Government:}

- Working to include the inclusion of CCS in EU ETS system;

- Supporting research, development and demonstration to increase environmental performance and reduce costs of CCS;

- Developing safety and monitoring standards;

- Including CCS in legal and regulatory frameworks (e.g. London Convention, ETS, CDM) and adjusting current legislation to make CCS possible, especially regarding storage;

- Providing (financial) guarantees for investment in CCS, especially in the start-up phase of the implementation; Industry:

- Increasing research and development into CCS and developing demonstration projects (along the entire CCS chain);

- Developing risk assessment and monitoring protocols; Research institutions:

- Increasing understanding of when CCS would be economical and competitive;

- Conducting research to improve the capture efficiency and storage safety, and developing risk assessment and monitoring protocols;

All stakeholders:

- Improving the public awareness of CCS.

Environmental NGOs are not listed as their role mainly consists of critically monitoring CCS implementation to ensure that CCS does not hinder (further) development and implementation of renewables and energy efficiency.

In this paper we have made an inventory of the position of different stakeholders in the Netherlands with respect to CCS; defined sustainability criteria; identified main concerns for CCS and developed a list of actions that should take place in the coming years. Further research will identify quantifiable indicators (by criterion), weights and trade-offs. This information, together with the results already obtained, will make possible to monitor whether the deployment of CCS contributes to the development of sustainable energy systems.

\section{Acknowledgements}

The authors wish to thank the following people for their input into this research: Dancker Damen (Leiden University), Jos 
Bruggink and Daniel Jansen (ECN), Sander de Bruyn (EC), Wouter de Ridder and Bert de Vries (MNP), Louis Goossens and Karel Mulder (TU Delft), Peter Hofman (TU Twente), Anne Kets (Rathenau Institute), Jos Post (RIVM), Mart van Bracht and Chris te Stroet (TNO), Maarten Gnoth and Huub Paes (Electrabel Nederland), Hans Hage (Corus), Jos Maas (Shell International), Jan Maas (Delta), Bert Stuij (SenterNovem), Marko Hekkert and Wim Turkenburg (Utrecht University),
Bram van Mannekes (NoGePa), Pieter Boet (Ministry of Economic affairs), Hans Spiegeler (VROM) and Jasper Vis (Natuur en Mileu). The authors are also grateful to Dan Birkket for linguistic assistance.

This research is part of a larger CCS program in the Netherlands called CATO, which has as main goal to assess whether or not CCS is a viable option for implementation in the Netherlands.

\section{Appendix A. Survey questionnaire}

\section{PART 1: Background information (question 1 out of 6)}

The survey comprises three parts:

- Six questions about your background

- Five questions about your vision on the role of CCS in the energy system

- Nine questions about points of concern regarding CCS with respect to a sustainable energy

system

In the survey we will use the abbreviation CCS for Carbon dioxide Capture and Storage

Question 1 (out of 6)

My age is between
0 - 30 years
46 - 60 years
$31-45$ years
$\mathrm{C}>60$ years

\section{Question 2 (out of 6)}

I work for

$\begin{array}{lll}\mathrm{O}_{\text {The power sector }} & \mathrm{O}_{\text {The government }} & \mathrm{O}_{\text {Environmental }} \\ \text { The oil industry } & \mathrm{O}_{\text {Scientific/research sector }} & \mathrm{O}_{\text {other }} \\ \mathrm{O}_{\text {The chemical industry }} & \mathrm{O}_{\text {A consultancy }} \\ \mathrm{O}_{\text {An engineering company }} & & \end{array}$

\section{Question 3 (out of 6)}

On average my time spent working on CCS issues is

Less than $5 \%$

Between $5 \%$ and $25 \%$

Between $50 \%$ and $75 \%$

Between 25 and $50 \%$

Between $75 \%$ and $100 \%$

Question 4 (out of 6)

My work is mainly

$\mathrm{O}$ Technically oriented

Economically oriented

$\mathrm{C}$ Policy oriented

Socially oriented

Environmentally/ecologically oriented

Other

Question 5 (out of 6)

My most relevant field of expertise regarding CCS

Technology (capture, storage, etc.)

Legal issues

Policy aspects

Economic feasibility and financing

Management

Risk aspects

Other

Question 6 (out of 6)

During the last national election I voted
Christian Democrats
Green Party
$\mathrm{O}$ Liberal party
Nationalist party 

Socialist party
Other right wing
Other left wing
Other / didn't vote / not applicable

PART 2: Your vision on the role of CCS in the energy supply (question 1 out of 5)

This part is about your vision on CCS with respect to a sustainable energy system.

I expect that CCS will play an important role

$\mathrm{C}$ for a short period of time (at the most for 30 years)

for a long period of time (more than 80

for a medium period of time (between 30 en years)

80 years)

Question 2(out of 5)

I expect that in the coming century CCS

$\mathrm{C}$ will not play a major role

$\mathrm{O}_{\text {will play a temporary role }}$

will play an important role as long as fossil fuels and storage capacity are available

\section{Question 3(out of 5)}

I hope that in the coming century CCS

$\mathrm{C}$ will not play a major role

$\mathrm{C}$ will play a temporary role

${ }$ will play an important role as long as fossil fuels and storage capacity are available

\section{Question 4 (out of 5)}

I see the role of $\mathrm{CCS}$ in reducing $\mathrm{CO}_{2}$ emissions as

C THE solution to combat climate change

Futile

Comparable to the role of energy saving and renewables

\section{Question 5 (out of 5)}

CCS is an important option because it is
Applicable on a large scale
Gives national industries opportunities to exploit technical know-how

Creates greater lead-time to develop costeffective renewables

PART 3: Your concerns with respect to CCS in a sustainable energy system (question 1 out of 9)

This part comprises nine questions with four corresponding statements. Each statement formulates a possible concern with respect to the role of CCS in (the development to) a sustainable energy system. Please choose the statement that best describes your opinion.

My greatest concern regarding CCS is

That it impedes the implementation of solar and wind energy

That international pipelines are difficult to manage

That there is no public acceptance for CCS
That there is no or little spin-off for renewable energy
Question 2 (out of 9)

My greatest concern regarding $\mathrm{CCS}$ is 
That $\mathrm{CO}_{2}$ leaks from underground reservoirs counteracting the effect of storage

That there is a danger for a large blow-out at the storage site

\section{Question 3 (out of 9)}

My greatest concern regarding CCS is

That the storage capacity for $\mathrm{CO}_{2}$ is insufficient

That $\mathrm{CO}_{2}$ leaks to an adjacent drinking water reservoir

\section{Question 4 (out of 9)}

My greatest concern regarding CCS is

$\mathrm{C}$ That the price of electricity will increase too much

$\mathrm{C}$ That poor countries do not have access to expensive CCS technology

\section{Question 5 (out of 9)}

My greatest concern regarding $\mathrm{CCS}$ is

That the development of renewable energy systems will be impeded

$\mathrm{C}$ That small-scale renewable energy will have little opportunity

Question 6 (out of 9)

My greatest concern regarding $\mathrm{CCS}$ is

That the balance of competition is disturbed

That casualties will continue to occur as a consequence of coal mining

\section{Question 7 (out of 9)}

My greatest concern regarding $\mathrm{CCS}$ is

$\mathrm{C}$ That we remain dependent on regions with large fossil fuel resources

That power plants will become more complex resulting in more power failures

\section{Question 8 (out of 9)}

My greatest concern regarding $\mathrm{CCS}$ is

That we place a burden on future generations because of the $\mathrm{CO}_{2}$ stored underground

That the supply of fossil fuels is unreliable
That we stay dependent on fossil fuels

That it impedes poor countries to develop their energy supply

That $\mathrm{CO}_{2}$ pipelines cross populated areas that may prove to be dangerous

That the costs will have negative effects on our standards of living

That it stimulates centralized large-scale energy supply (which might be less reliable than decentralized one)

That it diverts attention away from energy saving

That other environmental problems of energy supply are not solved

That there are not sufficient fossil fuel resources available

That companies will not invest in this technology

That we will become dependent on regions with large amounts of storage capacity

That it doesn't solve the environmental issue due to the continuing pollution from extracting and transporting fossil fuels

That environmental organizations are opposed to it

That storage locations will become a target for terrorist attacks

$\mathrm{C}$ That fossil fuels will become expensive

\section{Question 9 (out of 9)}

That future generations have to bear the costs of a transition to an energy supply based on renewables

That industrial production processes shut down more often because of the increased complexity

That other countries/regions will not implement CCS

c That climate change is a hype and CCS not required after that hype 


\begin{tabular}{|c|c|}
\hline Appendix B & \\
\hline $\begin{array}{l}\text { Mann-Whitney } \\
\text { chies among cri }\end{array}$ & $\begin{array}{l}\text { um Test-differences in hierar- } \\
\text { nationality }\end{array}$ \\
\hline Criteria & $\begin{array}{l}\text { P-Value for the comparison } \\
\text { between the 'Dutch respondents' } \\
\text { and 'Other nationalities' }\end{array}$ \\
\hline Clean & 0.094 \\
\hline Safe & 0.835 \\
\hline Flexible & 0.058 \\
\hline Justice & 0.141 \\
\hline Competitive & 0.090 \\
\hline Reliable & 0.836 \\
\hline Continuity & 0.058 \\
\hline Public acceptance & $0.015^{*}$ \\
\hline Independence & $0.012^{*}$ \\
\hline $\begin{array}{l}{ }^{*} \text { Failed the test. } \mathrm{T} \\
\text { two groups is great } \\
\text { statistically signifi }\end{array}$ & $\begin{array}{l}\text { nce in the median values between the } \\
\text { jould be expected by chance; there is a } \\
\text { rence. }\end{array}$ \\
\hline
\end{tabular}

\begin{tabular}{|c|c|c|}
\hline \multicolumn{3}{|l|}{ Appendix C } \\
\hline \multicolumn{3}{|c|}{$\begin{array}{l}\text { Mann-Whitney Rank Sum Test-differences in hierar- } \\
\text { chies among criteria by organization }\end{array}$} \\
\hline \multirow[t]{2}{*}{ Criteria/organization } & \multicolumn{2}{|c|}{$\begin{array}{l}\text { P-Value for the comparison } \\
\text { between the 'Dutch } \\
\text { respondents' and 'Other } \\
\text { nationalities' }\end{array}$} \\
\hline & $\begin{array}{c}\text { Public } \\
\text { acceptance }\end{array}$ & Independence \\
\hline Engineering/consultancy & 0.436 & 0.597 \\
\hline Chemical/oil industry & $0.029^{*}$ & 0.122 \\
\hline Power sector & 0.927 & 0.830 \\
\hline Environmental organizations & 0.714 & 0.905 \\
\hline Government & 0.405 & 0.493 \\
\hline Scientific/research sector & 0.150 & 0.237 \\
\hline
\end{tabular}

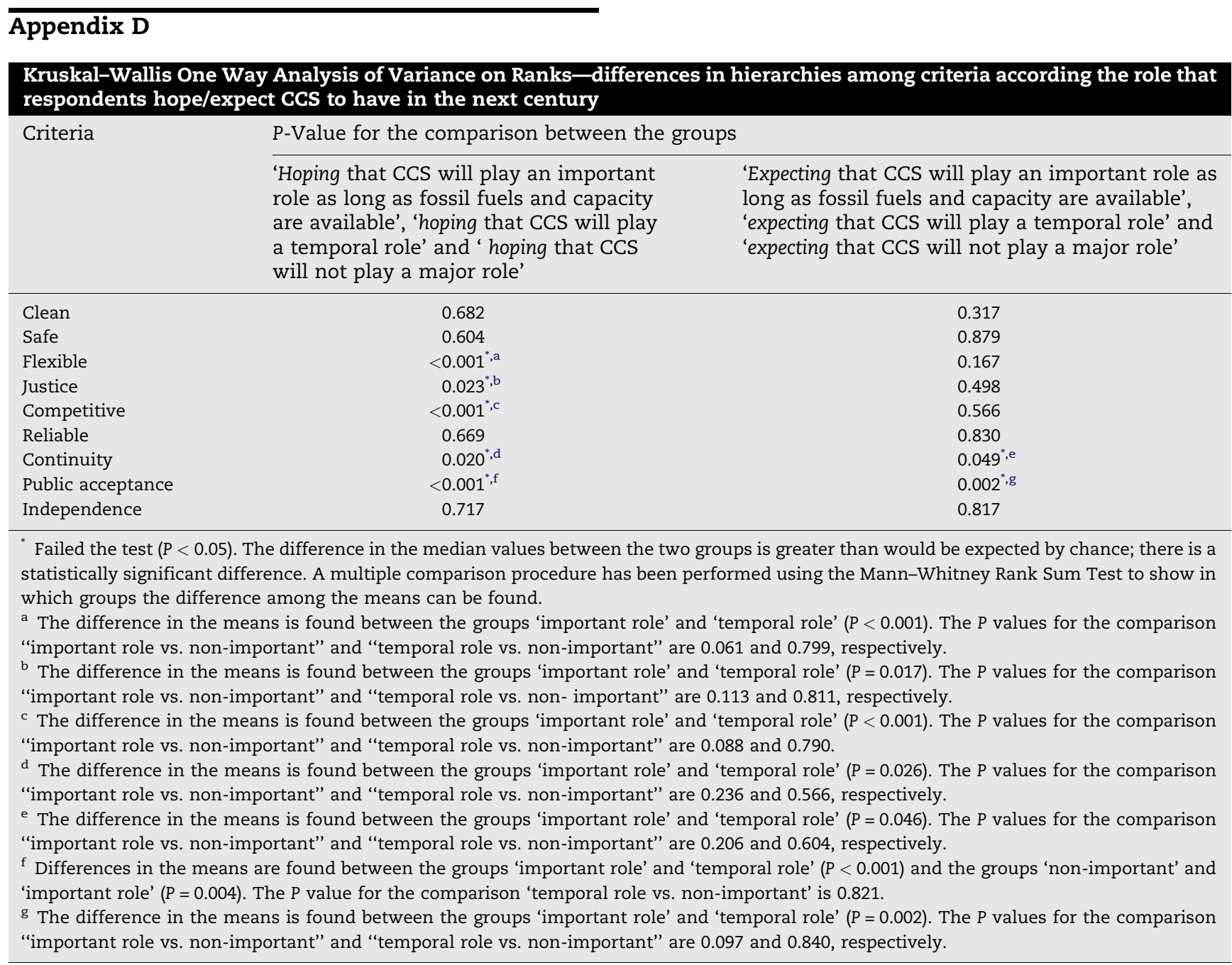




\section{R E F E R E N C E S}

Bachu, S., 2000. Sequestration of $\mathrm{CO}_{2}$ in geological media: criteria and approach for site selection in response to climate change. Energy Conv. Manage. 41, 953-970.

Best-Waldhober, M., Daamen, D., Damen, K., Faaij, A., 2006. Public perceptions and preferences regarding large scale implementation of six $\mathrm{CO}_{2}$ capture and storage technologies. Well-informed and well-considered opinions versus uninformed pseudo-opinions of the Dutch public. Centre for Energy and Environmental Studies, Faculty of Social Sciences, Leiden University and Copernicus Institute, Utrecht University, The Netherlands.

Bigdoli, H., 1996. A new productivity tool for the 90s: group support systems. J. Syst. Manage. 47 (4), 56-62.

Climate Action Network Europe, 2006. Position paper $\mathrm{CO}_{2}$ capture and storage, October 2006.

Colleman, D., Khanna, R., 1995. Groupware: Technology and Applications. Prentice-Hall, Upper Saddle River, NJ.

de Coninck, H., Anderson, J., Curnow, P., Flach, T., Flagstad, O., Groenenber, H., Norton, C., Reiner, D., Schackley, S., 2006. Acceptability of $\mathrm{CO}_{2}$ capture and storage. A review of legal, regulatory, economic and social aspects of $\mathrm{CO}_{2}$ capture and storage. Report ECN-C-06-026, ECN, Petten.

Damen, K., Faaij, A.P.C., Turkenburg, W.C., 2006. Health, safety and environmental risks of underground $\mathrm{CO}_{2}$ sequestration. Overview of mechanisms and current knowledge. Climatic Change 74 (1-3), 289-318.

Dennis, A., Wixom, B., 2001. Investigating the moderators of the group support system use with Meta-analysis. J. Manage. Inform. Syst. 18 (3), 235-259.

DeSantics, G., Gallupe, R., 1987. A foundation for the study of group decision support systems. Manage. Sci. 35 (5), 589609.

European Commission (EC), 2006. A European strategy for sustainable, competitive and secure energy. Energy Green Paper, COM (2006) 105 Final, Brussels.

EZ, 2005. Energy report 2005. Now for later. Ministry of Economic affairs. The Hague, Netherlands.

Friends of the Earth Europe, CAN Europe, Greenpeace, T\&E, WWF, 2005. Input from environmental NGOs at the start of the next round of the European Climate Change Program. Brussels. Available online at: http://www.foeeurope.org/ publications/2005/joint_position_paper_ECCP_oct_2005.pdf.

Froggatt, A., Teske, S., 2005. Invest in a Clean Energy Future! Greenpeace Exposes the EU's Dirty Energy Subsidies Greenpeace International, the Netherlands.

German Council for Sustainable Development, 2003. The perspectives for coal in a sustainable energy industry. Guidelines for a modern coal policy and the promotion of innovation, GCSD, September.

Geurts, J.L.A., Mayer, I., 1996. Methods for participatory policy analysis. Towards a conceptual model for research and development. Work Organization Research Centre Report 96.12.008/3, Tilburg, the Netherlands.

Heinimö, J., Pakarinen, V., Ojanen, V., Kässi, T., 2007. International bioenergy trade-scenario study on international biomass market in 2020. Report 181, Lappeenranta University of Technology, Department of Industrial Engineering and Management, Finland.
Hennicke, P., Fischedick, M., 2006. Towards sustainable energy systems: the related role of hydrogen. Energy Policy 34, 1260-1270.

Huber, G.P., 1984. Issues in the design of group decision support systems. MIS Quart. 8 (3), 195-205.

Jaccard, M., 2005. Sustainable Fossil Fuels. The Unusual Suspect in the Quest for Clean and Enduring Energy. Cambridge University Press, United Kingdom.

Lewandowski, I., Faaij, A., 2004. Steps towards the development of a certification system for sustainable Bio-energy trade. Report NWS-E-2004-31. Copernicus Institute, Utrecht University, the Netherlands.

Lewis, F., 1982. Facilitator: a micro-computer decision support system for small groups. Unpublished PhD dissertation. University of Lousville, Kentucky.

Metz, B., Davidson, O., de Coninck, H., Loos, M., Meyer, L. (Eds.), 2005. IPCC Special Report on Carbon Dioxide Capture and Storage. Intergovernmental Panel on Climate Change, Cambridge University Press.

PowerClean, $\mathrm{CO}_{2} \mathrm{NET}$ and CAME-GT, 2004. Strategy for sustainable power generation from fossil fuels. Available online at: http://www.co2net.com/infocentre/brochures/ EC\%20Network\%20Common\%20Strategy\%20FINAL\% 2020Nov04.pdf.

Ramírez, A., Junginger, M., Faaij, A., 2007. Sustainable energy systems: what are they? Copernicus Institute, Utrecht University (work in progress).

Reiner, D.M., Curry, T.E., de Figuerido, M.A., Herzog, H.J., Ansolabehere, S.D., Itaoka, K., Johnsson, F., Odenberger, M., 2006. American exceptionalism? Similarities and differences in national attitudes toward energy policy and global warming. Environ. Sci. Technol. 40, 2093-2098.

Schackley, S., McLachlan, C., Gough, C., 2005. The public perception of carbon dioxide and storage in the UK: results from focus groups and a survey. Climate Policy 4, 377-398.

Ter Mors, E., 2004. Credibility of CCS organization matters for attitude formation. Leiden Univeristy, presentation. Available online at: http://www.co2-cato.nl.

Ter Mors, E., Weening, M., Ellemer, N., 2005. Running head: understanding organizational credibility. Report 6-E1-05, Leiden University, The Netherlands, $16 \mathrm{pp}$.

Trumbo, C., McComas, W.K., 2003. The fuction of credibility in information processing for risk perception. Risk Anal. 23 (2), 343-353.

Turkenburg, W., 1997. Sustainable development, climate change and carbon dioxide removal. Energy Convers. Manage. 38 (Suppl), s3-s12.

United Nations, Division for sustainable development, 2001. Indicators of sustainable development: guidelines and methodologies. United Nations, Geneva.

Vickers, B., 1992. Using GSS to examine the future European automobile industry. Futures 24, 789-812.

WEHAB working group, 2002. A Framework for Action on Energy. World submit on sustainable development.

Wardekker, J.A., van der Sluijs, J.P., 2006. Evaluatie van Onzekerheidscommunicatie in de Milieubalans 2005, report NWS-E-2006-215, Department of Science, Technology and Society, Copernicus Institute for Sustainable Development and Innovation, Utrecht University, Utrecht, the Netherlands.

World Commission on Environment and Development (WCED), 1987. Our Common Future. Oxford University Press, New York. 